\title{
Research and Design of the Holiday lights Control System based on PLC
}

\author{
Yanyan Tian ${ }^{1, a}$ \\ ${ }^{1}$ Zhengzhou university of industrial technology Henan 451100, China \\ atyy0815@163.com
}

\begin{abstract}
In the paper the system designs holiday lights for hotel based on PLC control. The first design is to determine the overall program design according to demands of hotel. The hardware design function is selecting module CPU and giving the corresponding external wiring diagram. The most important part is software design of the system, including the software flow chart and the trapezoidal chart procedure design. Debugging system that has been designed and observing the results. After testing to verify the system is operating normally and meets the design requirements.
\end{abstract}

Key word: PLC,Holiday lights,SIEMENS.

\section{Introduction}

With the development of science and technology and the improvement of living standards, people for the increasingly high requirements of lights.This design is the use of PLC as the controller, with input and output module, control lantern show gorgeous pattern. The lantern lit sequence of a total of two, you can manually choose. This system also has the very big development space, can control more lights display more gorgeous pattern, add festive atmosphere to the festival.

\section{The overall design of the system}

The system design includes two parts: hardware and software, based on the working principle and technical performance of the control system, separating the hardware and the software design. The part of hardware design including the system block diagram, component selection, external wiring diagram, and then the hardware debugging, testing, in order to meet the design requirements. The software design part, first complete system function design block diagram and various modules in the overall design, drawing up detailed work plan; and then the specific design, including flow charts of each module, ladder diagram design, selection of appropriate software; finally, debugging, testing on the software into line, to achieve the desired functional 
requirements.

To control the characteristics of this system are analyzed: the design of holiday lights control system of a hotel, the system has 12 sets of lights, each group has 4 lights. The four lamps in each group are controlled by an output point.

Light is divided into the following two kinds, and light the time adjustable.

(1) in order to light: 1 group $\rightarrow 3$ group $\rightarrow 5$ group $\rightarrow 7$ group $\rightarrow 9$ group $\rightarrow 11$ group $\rightarrow 12$ group $\rightarrow 10$ group $\rightarrow 8$ group $\rightarrow 6$ group $\rightarrow 4$ group $\rightarrow 2$ group;

(2)1、 2 group $\rightarrow 3$ group $\rightarrow 2 、 3$ group $\rightarrow 4$ group $\rightarrow 3 、 4$ group $\rightarrow 5$ group.....

The analysis of characteristics of control system, input and output points can be determined. There are 12 groups of lights, no other control requirements, the digital output 12 points so we need. The system needs to switch control is lit, display mode selection switch to select display, time adjustment button two, respectively, to control the time increased $0.1 \mathrm{~S}$ and reduced $0.1 \mathrm{~S}$ time. So the need for digital input 4.The overall control system block diagram is shown in Fig.1.

\section{The system hardware design}

\section{A. Choose the type of CPU}

The system for the holiday lights control system, a total of 12 in the control group the lantern display a variety of ways, the system only list the two, actually has many. The control method can be very complex, program in large quantity, high stability requirements, so we choose CPU224 as the core controller.

\section{B. Module selection}

The design of the digital quantity input 4, 12 bit digital output. Containing 14 bit digital input selection in CPU224, 10 bit digital output. It requires additional configuration at least digital output points.The digital output module EM222 total of 5 kinds of products, which was 8 DC and 4 DC (5A), 8 AC, 8 point and 4 point relay relay (10A).

The configuration of I / $\mathrm{O}$ as much as possible when the configuration of 1-2 points, so the choice of EM222-4 DC (5A) module. The connection with the CPU diagram is shown in Fig.2 as below.

\section{System I / O distribution}

According to the experiment content and the request to realize the function, the I / O distribution. I / O distribution in the design of PLC are shown in Table1. 


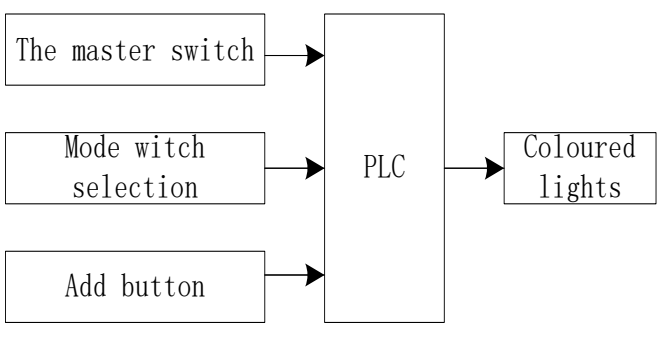

Fig.1 The system control structure

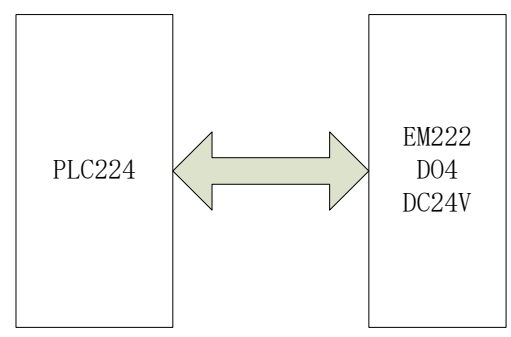

Fig.2 Module connecting mode

Table1 I / O distribution

\begin{tabular}{|c|c|c|}
\hline CPU224 & Address & Name and function \\
\hline \multirow{4}{*}{ Input } & $\mathrm{I} 0.0$ & The master switch \\
\hline & I0.1 & Mode selection switch \\
\hline & $\mathrm{I} 0.2$ & Time to add the button \\
\hline & $\mathrm{I} 0.3$ & Time decrease button \\
\hline \multirow{12}{*}{ Output } & Q0.0 & The first set of lights \\
\hline & Q0.1 & The Second set of lights \\
\hline & Q0.2 & The Third set of lights \\
\hline & Q0.3 & The Fourth set of lights \\
\hline & Q0.4 & The Fifth set of lights \\
\hline & Q0.5 & The Sixth set of lights \\
\hline & Q0.6 & The Seventh set of lights \\
\hline & Q0.7 & The Eighth set of lights \\
\hline & Q2.0 & The Ninth set of lights \\
\hline & Q2.1 & The Tenth set of lights \\
\hline & Q2.2 & The Eleventh set of lights \\
\hline & Q2.3 & The Twelfth set of lights \\
\hline
\end{tabular}

\section{The external wiring diagram}

Connection diagram of each part and the CPU is shown in Fig.3.

Connection diagram, SF0 and SF1 for the switch, K1 and K2 for the button. Switch SF0 system, SF0 is pulled down, lights began to light according to a certain sequence, cycle timer begins timing. SF1 represents the display mode selection switch, pull to the file according to the order of a lighting scheme, the plate to the next file lit in sequence scheme two. $\mathrm{K} 1$ is adjustable with a button, each time the cycle time increased by $0.1 \mathrm{~s}$. K2 is transferred by a button, each time the cycle time decreases $0.1 \mathrm{~s}$. Cycle time can be adjusted in the range of $0.2 \mathrm{~s} \sim 1.0 \mathrm{~s}$. 


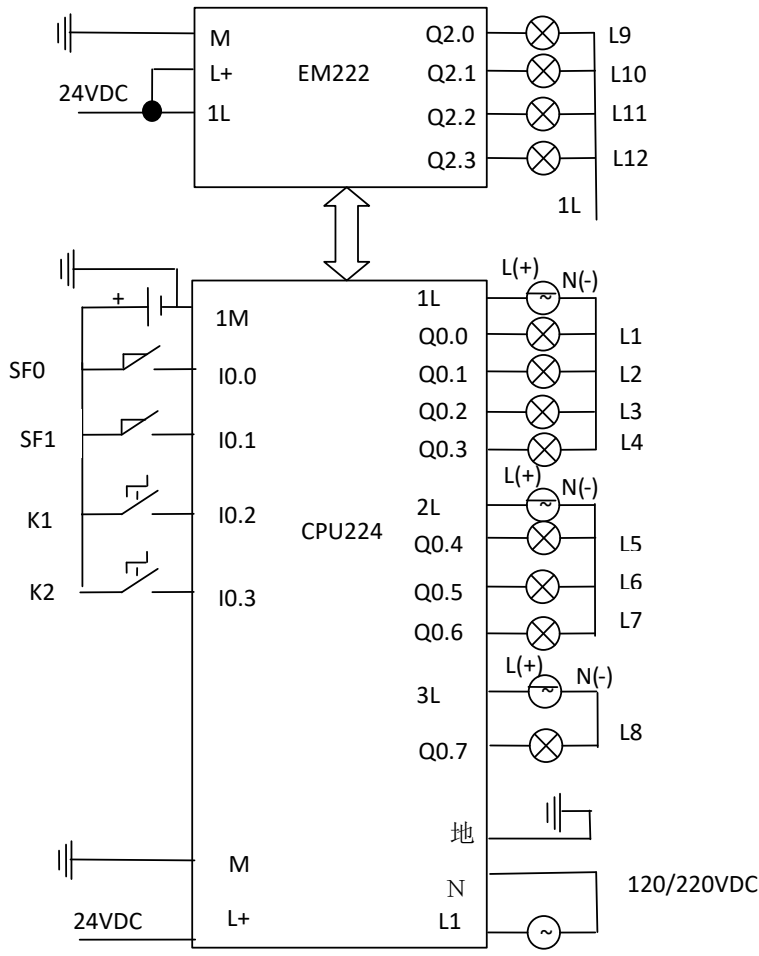

Fig.3 External wiring diagram

\section{System software design}

Design of control system in a hotel of holiday lights, the system has 12 sets of lights, each group has 4 lights.

(1)In order to light: 1 group $\rightarrow 3$ group $\rightarrow 5$ group $\rightarrow 7$ group $\rightarrow 9$ group $\rightarrow 11$ group $\rightarrow 12$ group $\rightarrow 10$ group $\rightarrow 8$ group $\rightarrow 6$ group $\rightarrow 4$ group $\rightarrow 2$ group; (2)1、2 group $\rightarrow 3$ group $\rightarrow 2 、 3$ group $\rightarrow 4$ group $\rightarrow 3$ 、 4 group $\rightarrow 5$ group..... Lantern cycle time $0.2 \mathrm{~s}-1 \mathrm{~s}$ control.

Control requirements: 12 groups of lanterns, each group of 4, a total of two kinds of light, can be selected manually. Every time a lantern lit, cycle time can be adjusted.

Implementation: the two switch two buttons as input signals for control, namely the total switch control is lit, the display of choice switch lights lit the way. Display control using look-up table method, to build a 12 group of lights display order form in the variable storage area, and then choose different display modes with different data pointer, and then use the pointer table look-up read out display, different display modes using different pointer. Time is adjusted by the two button control, a control cycle time plus $0.1 \mathrm{~s}$, another control cycle time reduction $0.1 \mathrm{~s}$.

According to the design requirements, the design of the program are the main program, and time control subroutine. 


\section{Summary}

This paper introduces the basic principle and working process of Festival Lights PLC control, the design is based on the S7-200 series CPU224 Germany Siemens company as the core control device. Through the hardware design, software debugging, this design realize to control lights Festival with a switch to select the display mode. After testing to verify the system is operating normally, reliable and meets the design requirements.

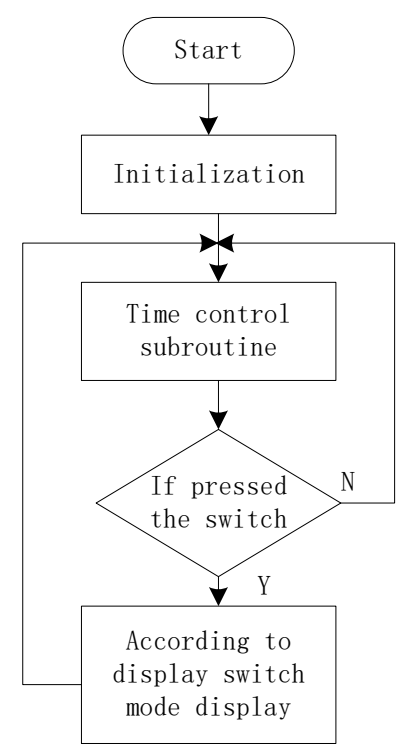

Fig.4 The main program flow chart

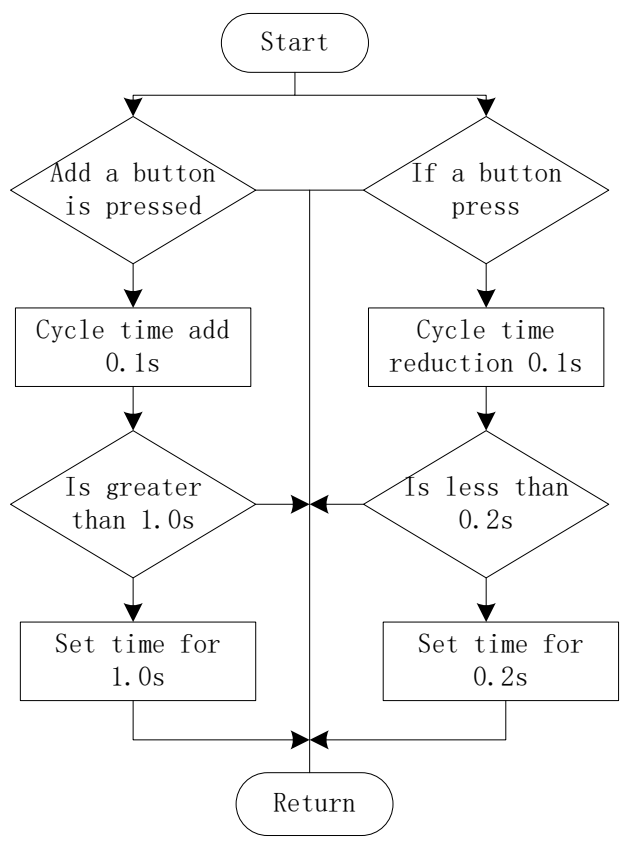

Fig.5 Time to adjust the subroutine

\section{References}

[1] Zhang Fengshan. Electrical control and PLC 2 edition [M] Beijing: China Light Industry Press, 2003

[2] Shi Guosheng. Electrical control and PLC Technology [M] Beijing: Chemical Industry Press, 2003

[3] Yu Hanqi. Electrical control and PLC application technology [M] Nanjing: Southeast University press, 2003

[4] Zhang Wanzhong. Programmable controller application technology [M] Beijing: Chemical Industry Press, 2001

[5] Ruan Youde. Electrical control and PLC training tutorial [M]. Beijing: People's Posts and Telecommunications Press, 2006

[6] Li Changjiu .Principle and application of PLC [M]. Beijing: Mechanical Industry Press, 2006.8 